\title{
Carcinoid of the uncinate process of the pancreas in a child: An unusual case
}

\author{
AK Chowdhury ${ }^{1}$, JU Ahmed ${ }^{2}$, M Chowdhury ${ }^{3}$, s Sarker ${ }^{4}$
}

\begin{abstract}
Carcinoid of the pancreas is rare among children. We treated a debilitating child who complained about post-prandial pain with a mass in upper abdomen, vomiting and weakness for a period of six months. Abdominal examination revealed an immobile, mildly tender, solid mass in the right lumbar region. Ultrasonography of abdomen demonstrated a tumour of head of the pancreas and ultrasonography-guided fine needle aspiration cytology of the mass suggested a malignant small round cell tumour. With Computed Tomogram an enhancing compact big mass was found at the head of the pancreas compressing the duodenum without invasion and metastasis. At exploratory laparotomy, we also detected a well-defined, rounded, big solid mass arising from uncinate process of the pancreas with no metastasis. After the excision of the mass along with a healthy portion of uncinate process, the patient recovered successfully. Histopathology evaluation showed a neoplasm composed of small nests and sheets of a dense cluster of malignant round cells with hyperchromatic nuclei, sometimes forming acini with stromal invasion. Diagnosis was malignant carcinoid of the pancreas, T2 N0 M0. At follow-up of three and a half years, the patient was found symptom-free and there was no evidence of recurrence.
\end{abstract}

Keywords: Carcinoid of the pancreas, Childhood, Excision, Recovery

\section{Introduction}

Adenocarcinoma is the commonest tumour of the pancreas (90\%). ${ }^{1}$ Pancreatic carcinoids constitute only $1-2 \%$ of pancreatic neoplasms and $2-3 \%$ of all carcinoids. ${ }^{2}$ These are indolent slow-growing tumours and become symptomatic at a late stage. Diarrhoea, flushing of the face, itching and wheeze, palpitation are common symptoms 3 . It is prevalent at the age of $40-60$ years and in a child, it is scarce 4 . We treated a child with a big malignant carcinoid of uncinate process of the pancreas that presented with postprandial abdominal pain, occasional vomiting and debilitating health. We performed local excision and achieved reasonable result. The unusual presentation, young age of the patient and the uncommon site of the disease encouraged us to present the case with useful information.

1. Dr. Ashish Kumar Chowdhury, MBBS, PhD, Former Associate Professor, Department of Surgery, University of Science and Technology Chittagong. Email:ashishkchowdhury1@gmail.com

2. Dr. Jashim Uddin Ahmed, FCPS, Professor and Head of the Department of Surgery, University of Science and Technology Chittagong

3. Dr. Mowsumi Chowdhury, MS (Phase-B), Sir Salimullah Medical College and Mitford Hospital, Dhaka

4. Dr. Satyam Sarker MS (Thesis part), Chittagong Medical College \& Hospital 


\section{Case Report}

A 13-year-old girl was admitted to the hospital with complaints of post-prandial upper abdominal pain, body-ache, occasional nonprojectile bilious vomiting and severe weakness of six months. On examination, we found her anaemic, dehydrated and malnourished with pitting leg oedema. Her pulse rate was 110 beats/minute and BP: $70 / 50 \mathrm{~mm} \mathrm{Hg}$. Palpation of the abdomen revealed a firm, mildly tender, immobile mass measuring about $7 \mathrm{~cm} \times 6 \mathrm{~cm}$ in the right lumbar region. There was no ascites, but bowel sound was present. Anorectal examination revealed no abnormality. Heart and lungs appeared normal clinically. Blood routine examination showed haemoglobin: $9.7 \mathrm{~g} / \mathrm{dl}$, WBC $10,200 / \mathrm{mm} 3$, ESR $30 \mathrm{~mm}$ in 1st hour, serum total bilirubin $0.8 \mathrm{mg} \%$, serum albumin 2.5 $\mathrm{g} / \mathrm{dl}$, serum amylase $152 \mathrm{IU} / \mathrm{L}$ and RBS 90 $\mathrm{mg} / \mathrm{dl}$. Serum electrolytes screening showed

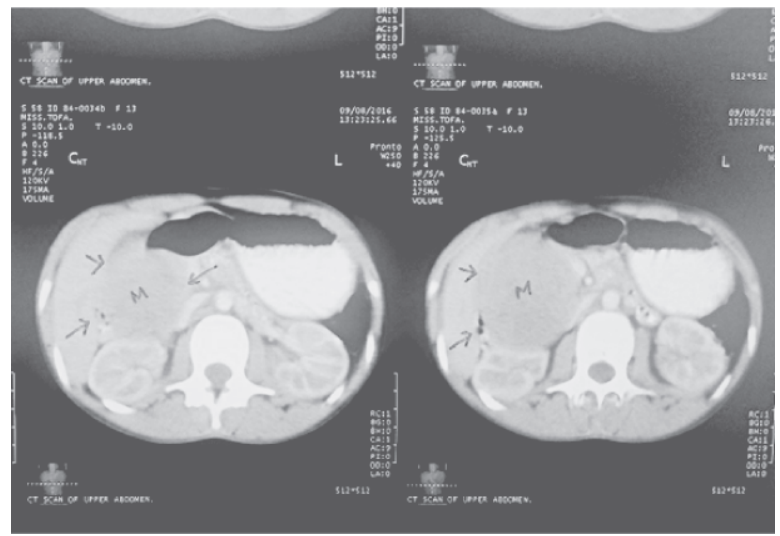

Figure 1: CT Abdomen demonstrating a well-defined mass at the head of the Pancreas compressing the duodenum

Hypokalaemia, Hyponatremia, and Hypochloraeamia. X-ray chest was normal. We performed an Ultra Sonogram (US) of the abdomen and found a $6.7 \mathrm{~cm} \times 6.6 \mathrm{~cm} \times 6.5$ $\mathrm{cm}$ mixed echogenic mass at the head of the pancreas with no evidence of ascites and lymphadenopathy. Gall bladder and bile duct were normal. The interpretation was a tumour of head of the pancreas. To know about the cytology of the mass we performed US guided FNA (Fine Needle Aspiration) smear which showed scattered and aggregates of small round cells with large hyperchromatic nuclei in the background of a little blood. The interpretation was a malignant round cell tumour. To know more about the tumour we performed contrast CT (Computed Tomogram) of abdomen which demonstrated a well-defined $6.7 \mathrm{~cm} \times 6.6 \mathrm{~cm} \times 6.5 \mathrm{~cm}$, rounded, heterogeneously enhancing mass arising in the head of the pancreas with no invasion to the bile and pancreatic ducts. But there was a widening of duodenal C-curve and sign of compression to it (Figure 01). Aorta, Portal Vein, Inferior Vena Cava, Superior Mesenteric Artery, stomach and small intestine were found normal.

The diagnosis was a malignant round cell tumour of the pancreas. We discussed with the parents the severity of the disease, the management protocol, and suggested treatment in a specialised centre that they denied and requested us to manage the patient in our hospital. Accordingly, after proper resuscitation and taking informed consent, we performed exploratory laparotomy by right upper transverse abdominal incision and observed a big, well-defined, rounded solid mass arising from the uncinate process of pancreas compressing the duodenum. The rest of the pancreas appeared to be normal. There was no sign of metastases in the abdomen. Pancreato-duodenectomy is the most recommended procedure for such a tumour. But for debilitating condition of the patient we considered as a high-risk operation while local excision was a considerably less risky procedure. We explained the situation to the parents of the patient and received their consent for local excision. Then we mobilised the tumour in all direction, removed the tumour along with a healthy portion of the uncinate process and put a drain tube there (Figure 02).

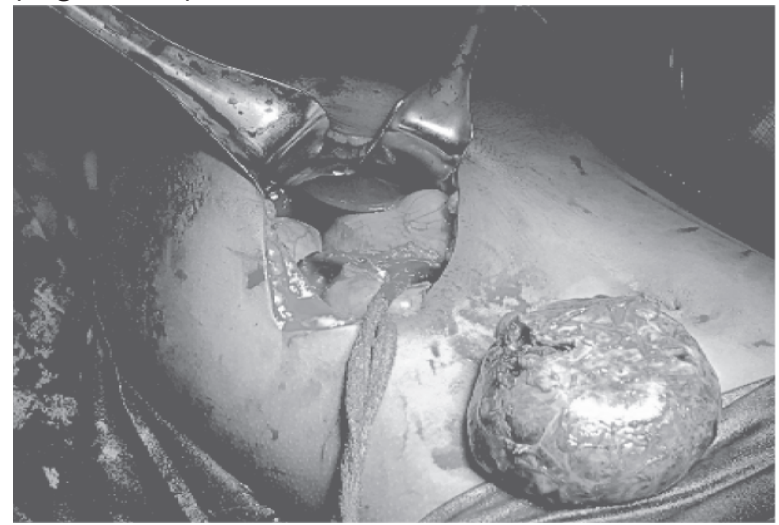




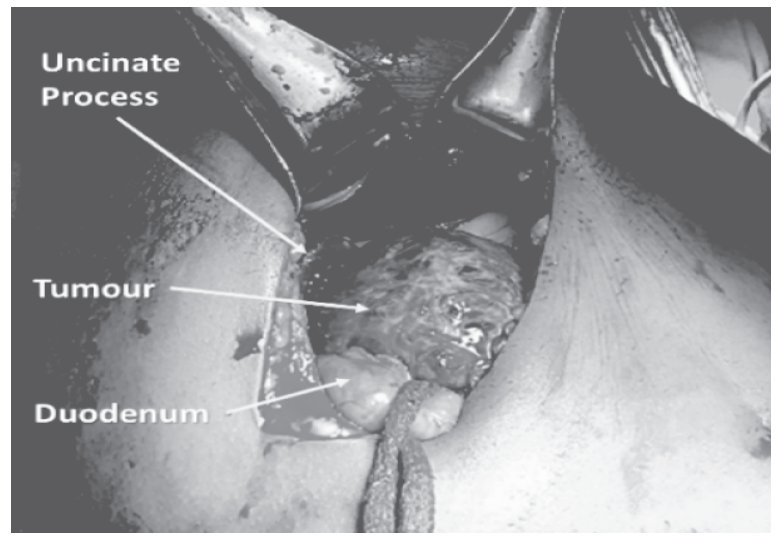

Figure 021, 02b: The pictures are showing mobilisation, and excision of the tumour

Post-operative period was uneventful. Histopathology evaluation of the specimen showed a malignant neoplasm composed of small nests and sheets of a dense cluster of round cells with hyperchromatic nuclei sometimes forming acini with stromal invasion (Figure 03).

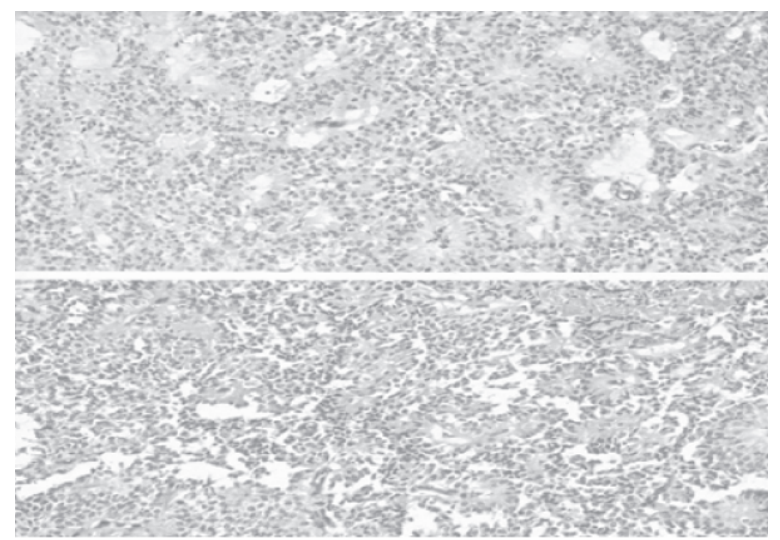

Figure 3: Histopathology (haematoxylin and eosin staining) slide shows malignant round cells with hyperchromatic nuclei forming acini with stromal invasion

The confirmed diagnosis was a malignant carcinoid of the pancreas T2 NO MO. We referred the patient to the oncologist for subsequent adjuvant therapy but the patient showed unwillingness. After three and a half years, the patient has no complain and there is no evidence of recurrence of the disease on radiology and imaging of the abdomen (Figure 4a, 4b and 4c).
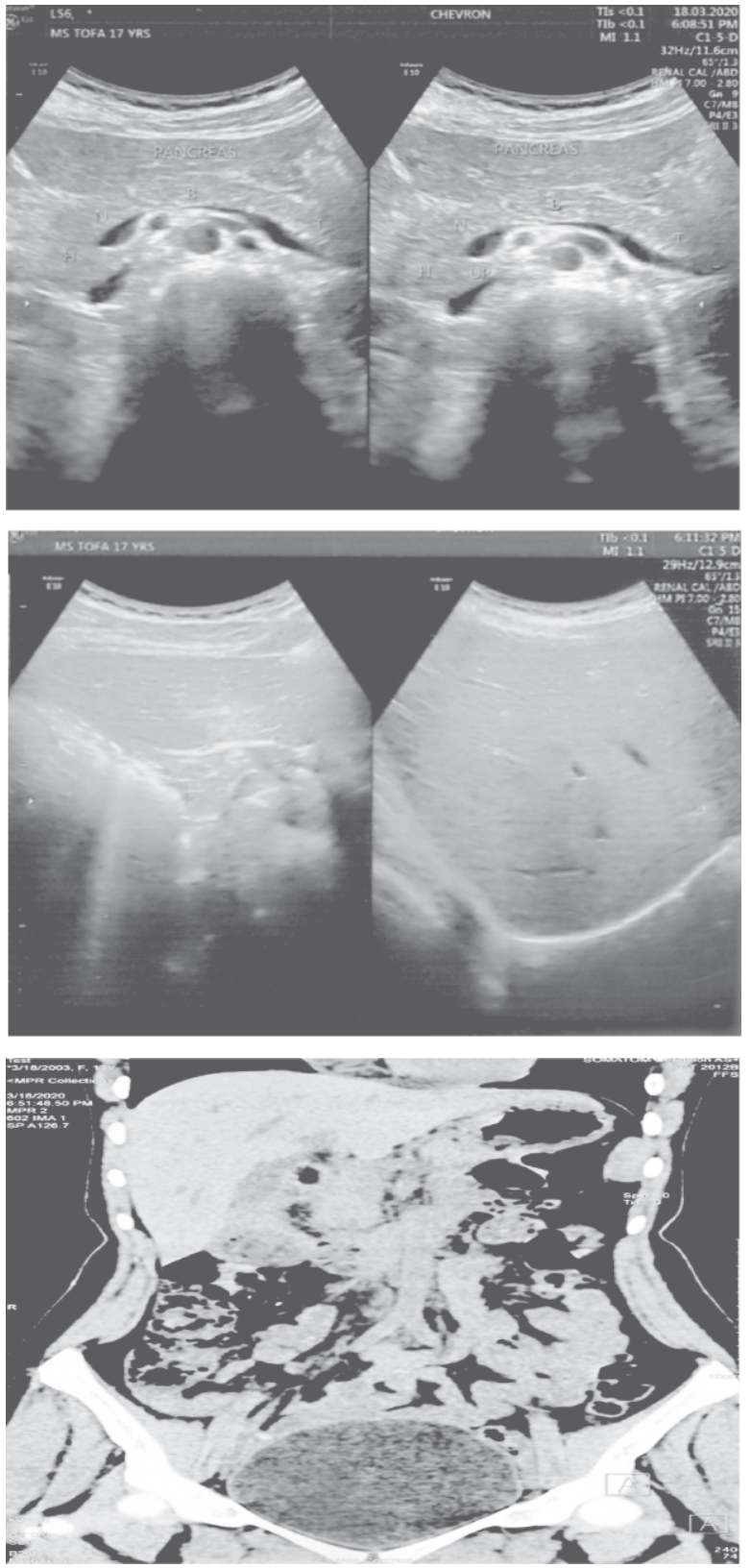

Figure 4a, 4b, and 4c: US and CT images of the abdomen shows normal pancreas, liver and other organs and no evidence of recurrence

\section{Discussion}

Carcinoid tumour commonly presents with the features of carcinoid syndrome. The cited case presented with post-prandial abdominal pain, occasional vomiting and feeling of a mass in the right upper abdomen an unusual presentation. In view of the young age of the patient we did not consider the mass to be a pancreatic tumour at first. In fact, at this age, 
Neuroblastoma, retroperitoneal rhabdomyosarcoma, nephroblastoma, non- Hodgkin's B-cell tumours are common neoplasms of the abdomen5, 6. However, Ultra Sonogram, US guidance FNAC (Fine Needle Aspiration Cytology) and CT interpretation suggested it was a Malignant Small Round Cell Tumour (MSRCT) at head of the pancreas that compressed the duodenum and this probably was the cause of postprandial pain and vomiting. As the patient did not present with the features of carcinoid syndrome, we did not evaluate serum serotonin and urine 5-hydroxyindoleacetic acid (5-HIAA) level as useful biochemical indicator of carcinoid. Pancreatico-duodenectomy with hepatic, duodenal and coeliac lymphadenectomy is a highly recommended procedure for malignant tumour of the head of the pancreas without distal metastasis. ${ }^{7-9}$ However, in a debilitating patient like this, we considered it as a high-risk procedure. So, we performed a local excision of the tumour after proper discussions and consent from the parents of the patient.

\section{Conclusion}

Post-prandial abdominal pain and vomiting is an unusual presentation of carcinoid of the uncinate process of the pancreas and may appear as a diagnostic dilemma for limitations. Though pancreatico-duodenectomy is the most recommended operation, it is a high-risk procedure for a debilitating patient. In such circumstances, a local excision may be considered as a useful option.

\section{Learning points}

1. Post-prandial abdominal pain, vomiting and feeling of a mass may be an unusual presentation of a significant size carcinoid of the uncinate of the pancreas.

2. In particular cases adequate local excision may be a surgical option with reasonable results.
Conflict of interest:

All authors showed a common interest.

\section{Acknowledgement}

We are grateful to Professor Dr. PB Roy FRCS, FCPS for revising the article and Dr. Zillur Rahman M. Phil, PhD, Professor of the Department of Pathology, Chittagong Medical College, for histopathology evaluation support. We are thankful to the patient and her parents for kind permission to use the treatment material and images in the manuscript.

\section{References}

1. M Farquharson. Surgery of the pancreas, spleen and adrenal glands. In: Farquharson $M$, Hollingshead J, Moran B(ed). Textbook of Operative Surgery. 10th ed. India: Replica Press Pvt. Ltd; 2015; p341-352.

2. Tawnya LB, Keith DA, Rosa FH, Jason BF. Small Bowel Malignancies and carcinoid tumours. In: Barry WF, Denise CC, (ed). The MD Anderson Surgical Oncology Handbook. 5th Ed. New Delhi: Wolters Kluwer (India) Pvt Ltd. 2016; p 329339.

3. Olivier SM, Andrea C, Alessandro P, Roberto PR. A primary pancreatic carcinoid tumour with unusual clinical complaints: A case report. World Journal of Surgical Oncology 2004, 2:3; p 1-4.

4. Kareva MA, Orlova EM, Kuznetsov NS, Kats LE, Gurevich LE, Abrosimov AI, Peterkova VA.et al. Carcinoid syndrome in a child present with pancreatic somatotropinoma. Problems of endocrinology. 2011; 57:

5. Qureshi SS, Shrikhande S, Ramadwar M, Desai S, Visvanathan S, Seema S. et al. Desmoplastic small round cell tumor of the pancreas: An unusual primary site for an uncommon tumor, a journal of Indian 
association of paediatric surgeon, April-June 2011; vol-16 issue 2: p66-68

6. Devidoff A. Padiatric Abdominal Mass. In: Myers JA, Millikan KW, Saclarides TJ, (ed). Common Surgical Diseases. 3rd Ed. New York. Springer, NY; 2008, p251-252.

7. Das DK. Fine-needle aspiration (FNA) cytology diagnosis of small round cell tumors: value and limita-tions. Indian $\mathrm{J}$ Pathol Microbiol. Jul 2004; 47(3):309-18.

8. Rajwanshi A, Srinivas R, Upasana G. Malignant Small Round Cell tumours. Jcytol.2009Jan-Mar; 26(1):1-10.

9. Radovanovic D, Stavanovic D, Pavlovic I. Carcinoid of Pancreas: case report. Medicine Pregled. January 2009; 62(1-2): 83-6. 